\section{Compound BMPR2 gene mutations in a malignant variant of idiopathic pulmonary arterial hypertension}

\author{
Walter Serra, ${ }^{1}$ Nicola Marziliano, ${ }^{1-3}$ \\ Domenico Corradi, ${ }^{4}$ Francesca Brigati, ${ }^{4}$ \\ Mariano Intrieri, ${ }^{2}$ Nadia Sapere, ${ }^{5}$ \\ Vittoria Caporale, \\ Piera Angelica Merlini, ${ }^{3}$ Alfredo Chetta, ${ }^{6}$ \\ Diego Ardissino' \\ ${ }^{1}$ Cardiac-Lung and Kidney Department, \\ Cardiology Unit, University Hospital, \\ Parma; ${ }^{2}$ Department of Health Sciences, \\ University of Campobasso; ${ }^{3}$ Cardiac \\ Department, IV Division of Cardiology, \\ AO Niguarda Hospital, Milan; \\ ${ }^{4}$ Department of Biomedical, \\ Biotechnological and Translational \\ Sciences (S.Bi.Bi.T.), Unit of Pathology \\ University of Parma; ${ }^{5}$ University of \\ Molise, Campobasso; ${ }^{6}$ Respiratory \\ Disease and Lung Function Unit, \\ Department of Clinical \& Experimental \\ Medicine, University of Parma, Italy
}

\section{Abstract}

Pulmonary arterial hypertension (PAH; MIM 600799 ) is frequently associated with concomitant diseases, including congenital heart disease. $6 \%$ of patients with PAH show a family history of the disease [hereditary PAH (HPAH)], with the major genetic determinants of HPAH being heterozygous germline mutations in the bone morphogenetic protein type II receptor (BMPR2). We present the case of a 38-year-old woman of Indian descent; initially admitted with progressive dyspnea [New York Heart Association (NYHA) class III]. The results of the proband's clinical assessments are presented here. Cardiac catheterization confirmed idiopathic PAH with severe right ventricular hypertrophy associated with pulmonary arteriopathy. Initial treatment comprised the dual endothelin receptor antagonist, bosentan, furosemide, warfarin and intravenous infusion of prostaglandin I2 (PGI2) for 3 days. Despite this, the patient died of pulmonary hemorrhagic edema and cardiogenic shock after 6 days of intensive care. After relatives' consent, post mortem assessments confirmed a diagnosis of $\mathrm{PAH}$; the heart displayed significant right ventricular hypertrophy and it was particularly noted that the right atrial appendage had undergone extreme dilation. Pulmonary arteriopathy was characterized by medial hypertrophy, arterialization of muscular arteries and muscularization of non-mus- cularized distal arteries. Molecular genetic analyses revealed the presence of cis-mutations in the BMPR2 gene (p.Cys123Arg and p.Arg332X). Cosegregation studies were not available.

Our findings suggest that mutations of the BMPR2 gene gave rise to the onset of $\mathrm{PAH}$ in this patient and that the severity of the onset and progression could be attributed to the presence of multiple mutations in a genedosage manner.

\section{Introduction}

Pulmonary arterial hypertension (PAH) (Table 1), ${ }^{1}$ is a rare, fatal disease of the pulmonary arterioles, ${ }^{1,2}$ where vasoconstriction and vascular remodeling lead to a progressive increase in pulmonary arterial pressure resulting in right ventricular failure. ${ }^{2,3} \mathrm{PAH}$ has an estimated prevalence of $15-50$ cases per million, ${ }^{4}$ the majority of which arise as a result of concomitant diseases (associated $\mathrm{PAH}$ ) which include congenital heart disease, connective tissue disorders and infection with the human immunodeficiency virus. Spontaneouslyoccurring, idiopathic PAH (IPAH) accounts for at least $40 \%$ of the remaining cases and typically affects around twice as many women as men with a median age at diagnosis of around 47 years, although the disease may occur at any age ${ }^{5-7} \mathrm{~A}$ genetic contribution to $\mathrm{PAH}$ has long been identified and $6 \%$ of patients with PAH have reported a family history of the condition [hereditary PAH (HPAH)]. ${ }^{8,9}$

Heterozygous germline mutations in the bone morphogenetic protein type II receptor 2 gene (BMPR2) have been identified in 10 to $40 \%$ of patients with apparently sporadic IPAH $^{10-13}$ and in 58 to $74 \%$ of patients with HPAH. ${ }^{14-16}$ BMPR2 is a member of the transforming growth factor- (TGF-) receptor superfamily; mutations in genes of several members of this family have been implicated in the onset of $\mathrm{PAH}$, indicating that the pathways controlled by members of this family are important to the integrity of the pulmonary vasculature (Table 2). ${ }^{17-19}$ Furthermore, the pore-forming subunit, Kv1.5, forms functional voltage-gated potassium channels $(\mathrm{Kv})$ in the pulmonary artery smooth muscle cells and abnormal potassium channel Kv1.5 function encoded by KCNA5 mutations alone and associated with BMPR2 mutations have been reported in patients with IPAH. ${ }^{20}$

In the present case report, we describe the clinical and molecular genetic assessment of a 38-year-old woman of Indian descent who was admitted to our hospital because of progressive dyspnea [New York Heart Association (NYHA) class III]. These assessments led to a diagnosis of $\mathrm{PAH}$ and the identification of a
Correspondence: Walter Serra, Cardiac-Lung and Kidney Department, Cardiology Unit, University Hospital, via A. Gramsci 14, 43100 Parma, Italy. Tel.:+39.0521.704629 - Fax:+39.0521.702189.

E-mail: wserra@libero.it,

Key words: BMPR2, idiopathic pulmonary arterial hypertension.

Contributions: SW, CD, PMA and DA conceived the clinical and therapeutic patient's approaches; NM, NS and MI performed the molecular analyses, CD and BF performed the pathological examinations; WS performed the clinical investigations. All authors read the manuscript in the present form and agreed to the submission.

Funding: MN and the genotyping carried out in this work were funded by the following grant: RF2010-2313451 (Hypertrophic cardiomyopathy: new insights from deep sequencing and psychosocial evaluations). Medical writing assistance was provided by Apothecom scopemedical and funded by Actelion Pharmaceuticals Ltd.

Conflicts of interests: the authors declare no conflicts of interests.

Received for publication: 11 November 2015

Revision received: 29 November 2015.

Accepted for publication: 5 December 2015.

This work is licensed under a Creative Commons Attribution NonCommercial 3.0 License (CC BYNC 3.0).

(C) Copyright W. Serra et al., 2014

Licensee PAGEPress, Italy

Cardiogenetics 2014; 4:4824

doi:10.4081/cardiogenetics.2014.4824

double heterozyogosity of the BMPR2 gene. The patient subsequently died of pulmonary hemorrhagic edema and cardiogenic shock after 6 days of intensive care. It can be speculated that the early onset, severity of progression and fatal outcome of the disease can be explained un the light of the two-hits hypothesis as reported by Wang et al. ${ }^{20}$

\section{Materials and Methods}

\section{Clinical assessments}

Physical and cardiac examinations included chest X-ray, 12-lead electrocardiogram (ECG), echocardiography, computed axial tomography (CAT) (3D reconstruction) and laboratory tests. Transthoracic echocardiography examinations were performed using an iE33 xMATRIX echocardiography system equipped with 2.5-3.5 $\mathrm{MHz}$ probes (Phillips Healthcare, Surrey, UK) which provided a non-invasive assessment of pulmonary artery pressure and 
a useful means of monitoring the patients' condition.

\section{Histology}

Tissue samples collected during the postmortem examination were fixed in a $10 \%$ buffered formalin solution for approximately $48 \mathrm{~h}$ and subsequently embedded in paraffin tissue blocks using standard histopathology methods [formalin-fixed paraffin embedded (FFPE)]. Histological sections, $3 \mu \mathrm{m}$ in thickness, were obtained from each block and stained with hematoxylin-eosin. Selected samples were also stained using the Weigert method for elastic fibers and immunohistochemically tested using anti-smooth-muscle actin, anti-CD3 and anti-CD20 primary antibodies in order to highlight the pulmonary artery tunica media or the potential inflammatory infiltrate.

\section{Mutation analysis}

After informed consent of both living parents, genomic DNA of the index case was extracted from FFPE by means of the Maxwell $16^{\mathrm{TM}}$ platform (Promega). The BMPR2, SMAD, TGFBR1, TGFBR2, ACVR1, ACVRL1, BMP9/GDF2, KCNK3, KCNA5, CAV1, ENG and $S M A D 2$ genes screening was performed on a PGM platform (IonTorrent, LifeTechnologies) equipped with a 318 chip (www.lifetechnologies.com); sequence variants have been subsequently confirmed by conventional forward and reverse Sanger Sequencing on the ABI PRISM 3130XI.

Modeling: potential detrimental modifications induced by the mutations on DNA and protein level were assessed by: i) PolyPhen-2 (genetics.bwh.harvard.edu/pph2/) and Sift (sift.jcvi.org/); ii) PyMol (http://pymol.sourceforge.net) and MODELLER (Accelerys, San Diego, CA, USA) softwares.

\section{Results}

\section{Clinical findings}

The patient had been treated for respiratory disease for almost 3 years but there was no history of syncope, palpitation, chest pain or hemoptysis. Cardiac examinations showed: i) the patient had a heart systolic murmur; ii) the 12-lead ECG revealed sinus tachycardia, right axis deviation and right ventricular hypertrophy with strain; iii) the chest X-ray revealed cardiomegaly and features of pulmonary hypertension and bilateral pleural effusion; iv) chest CAT (3D reconstruction) showed a pulmonary artery trunk diameter of $39 \mathrm{~mm}$ and a ground glass area without pulmonary thromboembolism. Of note, an enlarged right ventricle and smaller left ventricle were observed and the septum was pushed towards the left ventricle due to very high pressure inside the right ventricle (Figure 1A and B).

Transthoracic echocardiogram revealed: i) right ventricular systolic pressure of $96 \mathrm{~mm} / \mathrm{Hg}$ (the peak of gradient through a severe tricuspid regurgitation was $76+20 \mathrm{mmHg}$ of right atrial pressure, by the dilatation without collapsing vena cava; Figure 1C and D); ii) dilatation of the right chambers (the right atrium had a diameter of $57 \mathrm{~mm}$, a wall measurement of $10.5 \mathrm{~mm}$ and a pulmonary artery trunk measurement of up to $38 \mathrm{~mm}$; Figure 1E).

Evidence for right ventricular dysfunction was shown by a low value of tricuspid annular post-systolic excursion (TAPSE $3:<10 \mathrm{~mm}$, severely abnormal). The acceleration time of pulmonary outflow (ACTpo) was $40 \mathrm{~ms}$. There was no evidence of left to right atrial shunt.

Laboratory investigations excluded infections and immunological diseases. Cardiac catheterization confirmed severe PAH: 115/15

Table 1. Clinical classification of pulmonary hypertension according to the European Society of Cardiology (ESC) and the European Respiratory Society (ERS) guidelines. ${ }^{1}$

\section{Classification of pulmonary hypertension}

$\begin{array}{ll}\text { PAH } & \text { Idiopathic PAH } \\ & \text { Hereditable PAH } \\ & \text { Drug-and toxin-induced } \\ & \text { Persistent PH of the newborn } \\ & \text { Associated PAH } \\ & \text { Connective tissue disease } \\ & \text { HIV infection } \\ & \text { Portal hyptertension } \\ \text { Congenital heart disease } & \text { Schistosomiasis } \\ \text { Chronic hemolytic anemia }\end{array}$

\section{$\mathrm{PH}$ due to left heart disease}

PH due to lung disease $\quad$ Chronic obstructive pulmonary disease

\section{Chronic thromboembolic pulmonary hypertension}

PH with unclear multifactorial mechanisms Interstitial lung disease

PAH, pulmonary arterial hypertension.
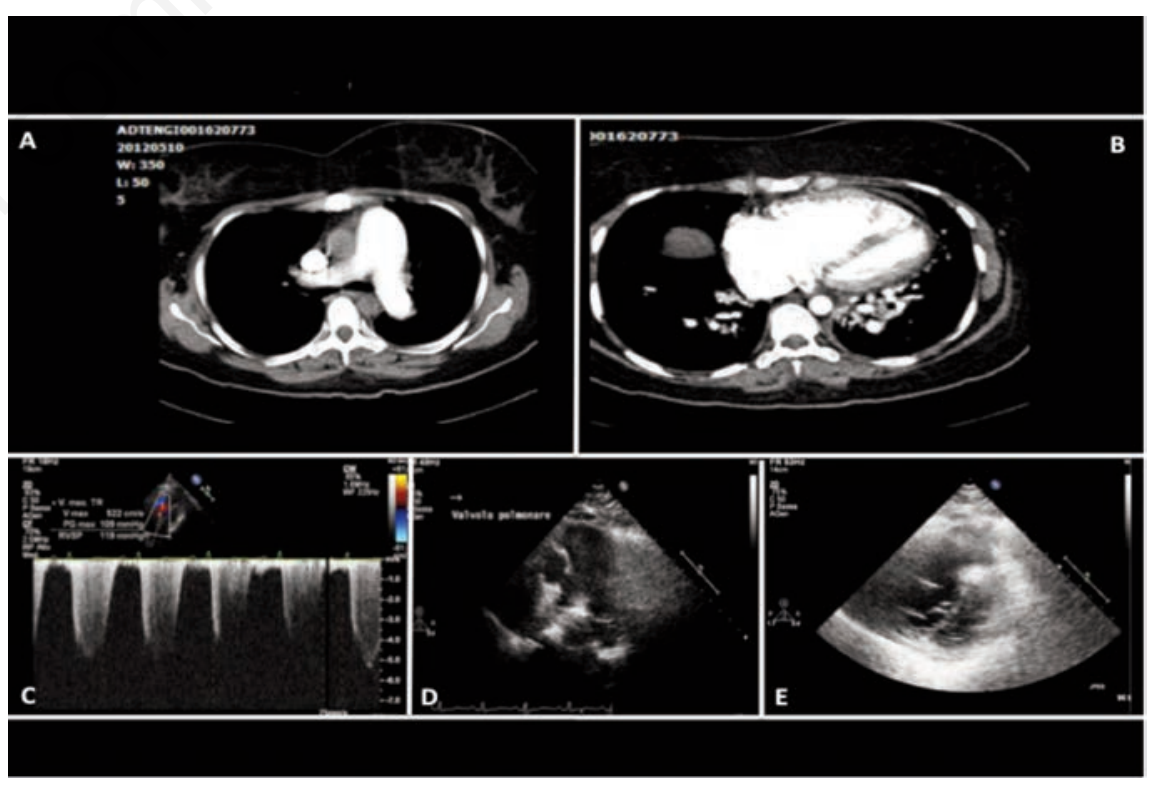

Figure 1. Cardiac imaging. A) and B) Computed tomography scans demonstrating severe idiopathic pulmonary arterial hypertension. Note the markedly enlarged pulmonary trunk with tiny branching smaller vessels. C) A transthoracic echocardiogram revealed a right ventricular systolic pressure of $96 \mathrm{~mm} / \mathrm{Hg}$. D) A pulmonary artery trunk measuring up to $38 \mathrm{~mm}$ was detected. E) Dilatation of right chambers: right atrium was $57 \mathrm{~mm}$ in diameter; right ventricle wall measurement was $10 \mathrm{~mm}$. 
$\mathrm{mmHg}$, mPAP 65mm/Hg, PCWP $14 \mathrm{~mm} / \mathrm{Hg}$, IC: $2 \mathrm{~L} / \mathrm{m} / \mathrm{mq}$ and pulmonary vascular resistance of $26 \mathrm{UW}^{2} \mathrm{O}_{2}$ saturation of $50 \%$ at the RA, $100 \%$ at the left upper pulmonary vein; $90 \%$ at the left atrium, $65 \%$ at the RV, $60 \%$ at the left pulmonary artery and $86 \%$ at the femoral artery. The aortic pressure was 92/62 (mean 44) mmHg. After adenosine $100-200-300 / \mathrm{kg} / \mathrm{min}$ PVR were unchanged. Coronary tree was normal.

\section{Treatment for idiopathic pulmonary arterial hypertension}

Following a diagnosis of severe $\mathrm{PAH}$, treatment was initiated with bosentan $125 \mathrm{mg} /$ day, diuretic (furosemide $125 \mathrm{mg}$ ), warfarin and intravenous infusion of prostaglandin $\mathrm{I} 2$ (PGI2) infusion for 3 days and non-invasive ventilation therapy (using a continuous positive airway pressure mask). However, no benefit was seen following these treatments and the patient subsequently died of pulmonary hemorrhagic edema and cardiogenic shock after 6 days of intensive care.

In this case a massive pulmonary edema may be due to the very high values of pulmonary pressure that led to flooding of the pulmonary alveoli and by a respiratory distress syndrome favored by the presence of an acute bronchopneumonia.

A pulmonary veno-occlusive hypertension disease was excluded from high-resolution computed tomography and capillary pulmonary wedge pressure (PCWP) was below $15 \mathrm{~mm} / \mathrm{Hg}$.

\section{Gross and microscopic appearances}

\section{Lungs}

At necropsy (Figure 2 A-D), both lungs (each $590 \mathrm{~g}$ ) showed diffuse endoalveolar hemorrhage and marked changes in all of the pulmonary arterial branches especially in terms of wall thickening.

\section{Heart}

The heart $(470 \mathrm{~g})$ displayed significant right ventricular hypertrophy; the right atrial appendage had undergone extreme dilation to the extent that it was incorporated into the main right atrial chamber. Histopathology (Figure 3A-D) revealed pulmonary arteriopathy which was characterized primarily by medial hypertrophy, arterialization of muscular arteries and muscularization of non-muscularized distal arteries. Focal intimal fibrosis and mild plaques were detectable throughout the lung parenchyma. There were neither thrombotic lesions nor signs of pulmonary veno-occlusive disease.

\section{Molecular findings}

Molecular investigations on the index case identified two BMPR2 mutations; the first was a missense mutation in exon \#3 (p.Cys123Arg) and the second was a stop codon mutation in

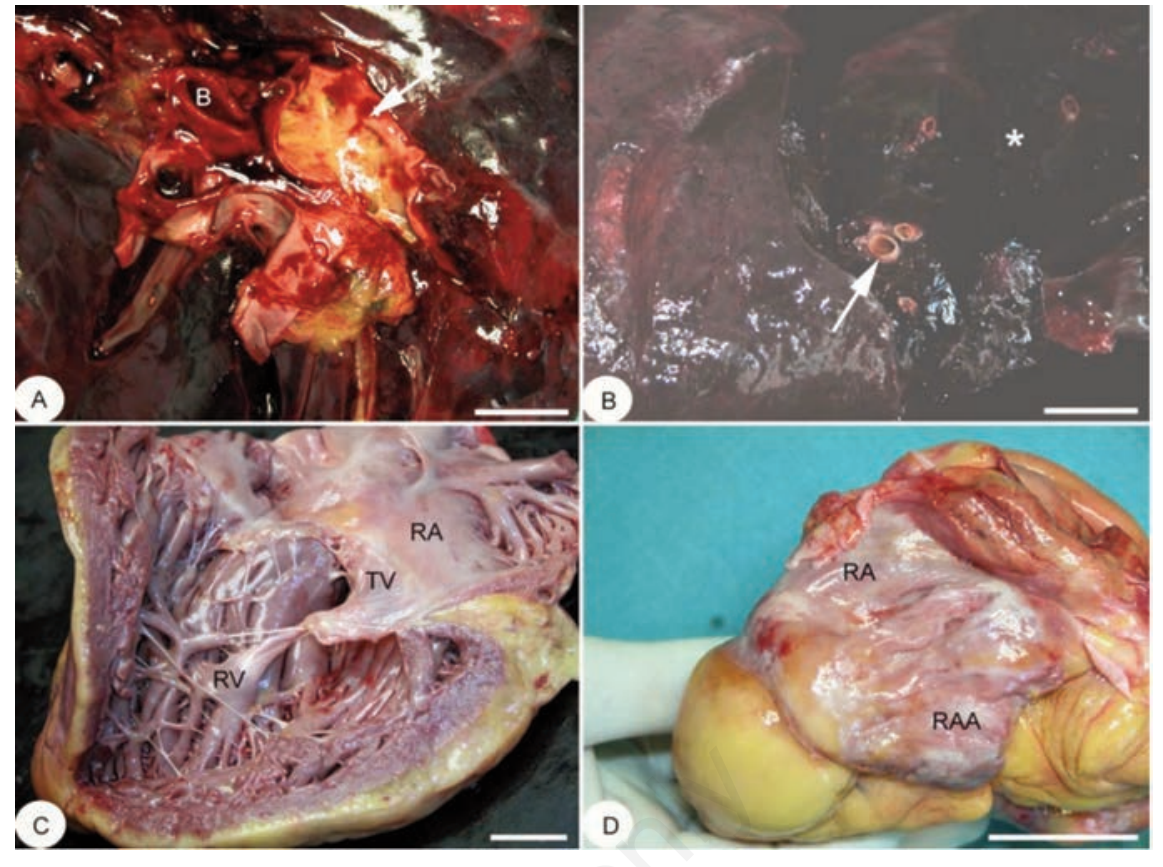

Figure 2. Autopsy images. A) The right lung hilus with an exceedingly thick pulmonary artery (arrow) which shows an aortic-like appearance. B) On cut section, the lung parenchyma (asterisk) is extremely hemorrhagic and displays rigid and thick peripheral pulmonary artery branches (arrow). C) The right ventricle is highly hypertrophic. D) The right-atrial appendage had undergone marked dilation and become part of the main right atrial chamber. Abbreviations: $B$, bronchus; $R A$, right atrium; RAA, right-atrial appendage; $R V$, right ventricle; TV, tricuspid valve. Size of bars A) and B): $3 \mathrm{~cm}, C$ ) and D): $2 \mathrm{~cm}$.

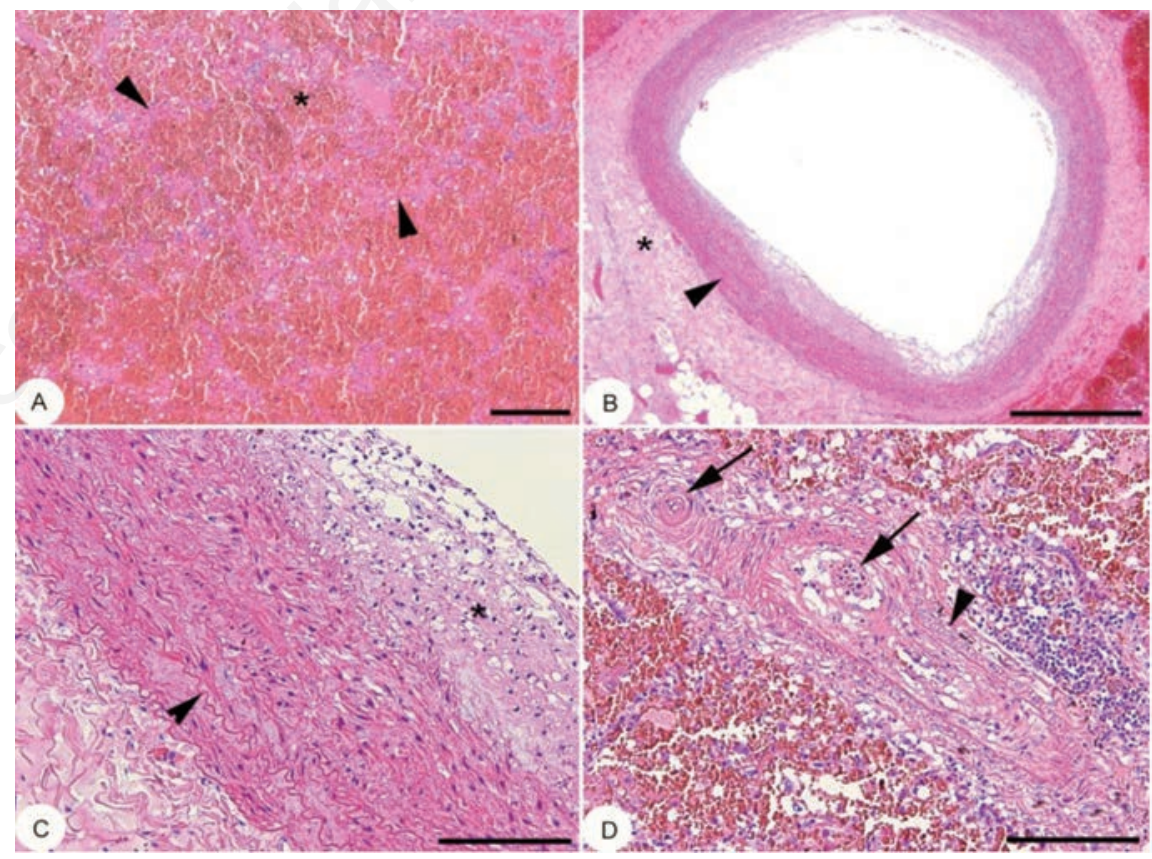

Figure 3. Histopathology. A) The lung parenchyma is diffusely modified by an endoalveolar hemorrhage (asterisk) which is delimited by the alveolar septa with exceedingly congested blood vessels (arrowheads). B) The greatest pulmonary artery roots display thickening of their wall (arrowhead) and periadventitial fibrosis (asterisk). C) In this close-up of picture B, the blood vessel wall is thickened as a result of tunica media (arrowhead) and tunica intima (asterisk) enlargement. The tunica media shows increased elastic fiber and smooth muscle cell components, thereby constituting a kind of arterialization. The tunica intima is characterized by fibrosis with edema and some mild inflammatory infiltrate. D) The peripheral pulmonary artery branches show marked thickening which is mainly secondary to smooth muscle cell proliferation. As a result, the relevant vessel lumens (arrows) are exceedingly narrowed. Hematoxylin-eosin staining. Original magnifications: A) x4 (bar $400 \mu \mathrm{m})$, B) x2 (bar $1 \mathrm{~mm})$, C) and D) x10 (bar $200 \mu \mathrm{m}) ;$ C) and D) x20 (bar $100 \mu \mathrm{m})$. 
Table 2. Characteristics of genes currently associated with the onset of idiopathic pulmonary arterial hypertension.

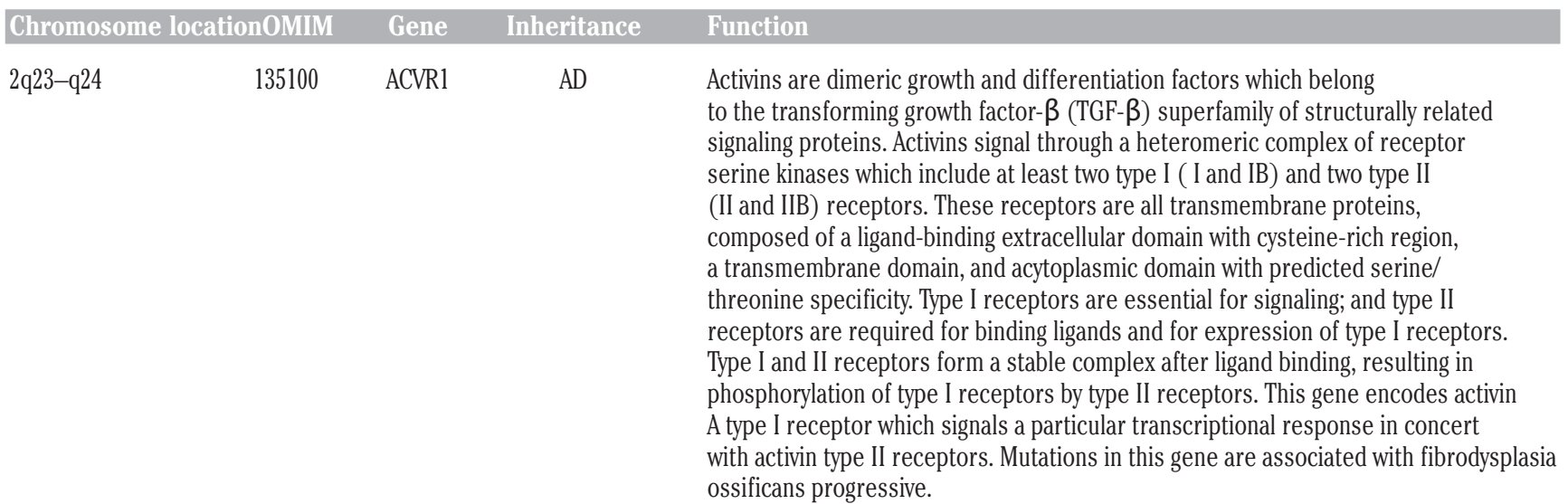

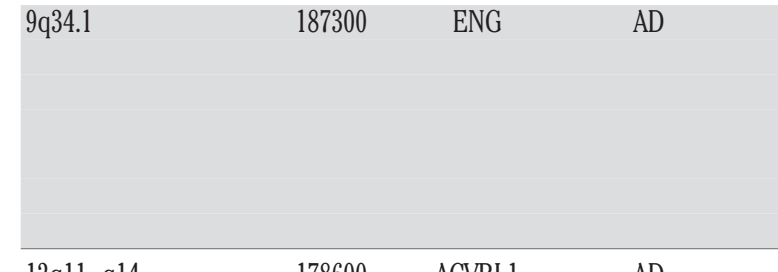

$12 q 11-q 14 \quad 178600 \quad$ ACVRLl $\quad$ AD

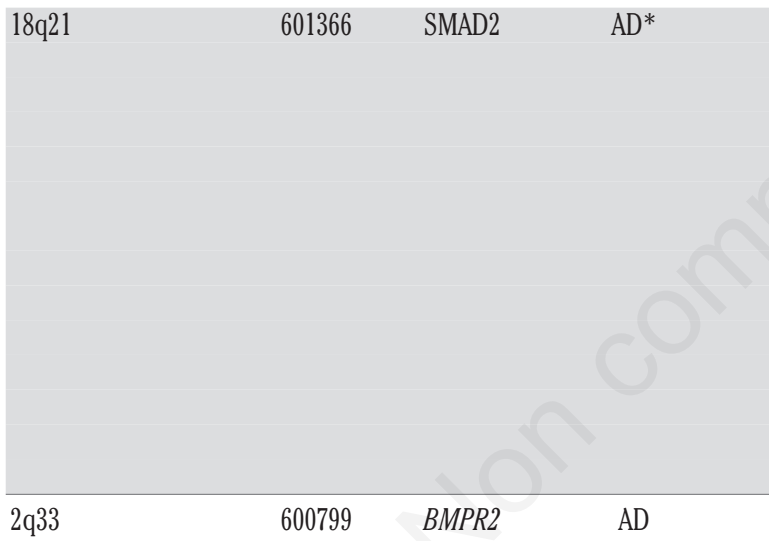

This gene encodes a homodimeric transmembrane protein which is a major glycoprotein of the vascular endothelium. This protein is a component of the transforming growth factor $\beta$ receptor complex and it binds TGFB1 and TGFB3 with high affinity. Mutations in this gene cause hereditary hemorrhagic telangiectasia, also known as Osler-Rendu-Weber syndrome 1, an autosomal dominant multisystemic vascular dysplasia. Alternatively spliced transcript variants encoding different isoforms have been found for this gene.

This gene encodes a type I cell-surface receptor for the TGF- $\beta$ superfamily of ligands. It shares with other type I receptors a high degree of similarity in serine-threonine kinase subdomains, a glycine- and serine-rich region (called the GS domain) precedingthe kinase domain, and a short C-terminal tail. The encoded protein, sometimes termed ALK1, shares similar domain structures with other closely related ALK or activin receptor-like kinase proteins that form a subfamily of receptor serine/threonine kinases. Mutations in this gene are associated with hemorrhagic telangectasia type 2, also known as Rendu-Osler-Weber syndrome 2.

The protein encoded by this gene belongs to the SMAD, a family of proteins similar to the gene products of the Drosophila gene 'mothers against decapentaplegic' (Mad) and the C. elegans gene Sma. SMAD proteins are signal transducers and transcriptional modulators that mediate multiple signaling pathways. This protein mediates the signal of the transforming growth factor (TGF) $\beta$, and thus regulates multiple cellular processes, such as cell proliferation, apoptosis, and differentiation. This protein is receptor activation (SARA) protein. In response to TGF- $\beta$ signal, this protein is pho phorylated by the TGF- $\beta$ receptors. The phosphorylation induces the dissociation of this protein with SARA and the association with the family member SMAD4.

The assciation with SMAD4 is important for the translocation of this protein into the nucleus, where it binds to target promoters and forms a transcription repressor complex with other cofactors. This protein can also be phosphorylated by activin type 1 receptor kinase, and mediates the signal from the activin. Alternatively spliced transcript variants have been observed for this gene.

This gene encodes a member of the bone morphogenetic protein (BMP) receptor family of transmembrane serine/threonine kinases. The ligands of this receptor are BMPs, which are members of the TGF- $\beta$ superfamily. BMPs are involved in endochondral bone formation and embryogenesis. These proteins transduce their signals through the formation of heteromeric complexes of two different types of serine (threonine) kinase receptors: type I receptors of about 50-55 kD and type II receptors of about 70-80 kD. Type II receptors bind ligands in the absence of type I receptors, but they require their respective type I receptors for signaling, whereas type I receptors require their respective type II receptors for ligand binding. Mutations in this gene have been associated with primary pulmonary hypertension, both familial and fenfluramine-associated, and with pulmonary venoocclusive disease.

\begin{tabular}{|c|c|c|c|}
\hline 13q13.3 & 615343 & $A D$ & $\begin{array}{l}\text { The scaffolding protein encoded by this gene is the main component of the caveolae } \\
\text { plasma membranes found in most cell types. The gene is a tumor suppressor gene } \\
\text { candidate and a negative regulator of the Rasp } 42 / 44 \text { mitogen-activated kinase cascade } \\
\text { Caveolin } 1 \text { and caveolin } 2 \text { arelocated next to each other on chromosome } 7 \text { and express } \\
\text { colocalizing proteins that form a stable hetero-oligomeric complex. Mutations in this } \\
\text { gene have been associated with Berardinelli-Seip congenital lipodystrophy. } \\
\text { Alternatively spliced transcripts encode } \alpha \text { and } \beta \text { isoforms of caveolin } 1 \text {. }\end{array}$ \\
\hline
\end{tabular}


Table 3. Mutations associated with the idiopathic pulmonary arterial hypertension phenotype.

\begin{tabular}{lcccc} 
Accesion number & Codon change & Amino acid change & Codon number & Disease \\
CM0101158 & tTGT->CGT & Cys->Arg & 123 & Primary pulmonary hypertension \\
CM010163 & tCGA->TGA & Arg->X & 332 & Machado et al. ${ }^{21}$ \\
\hline
\end{tabular}

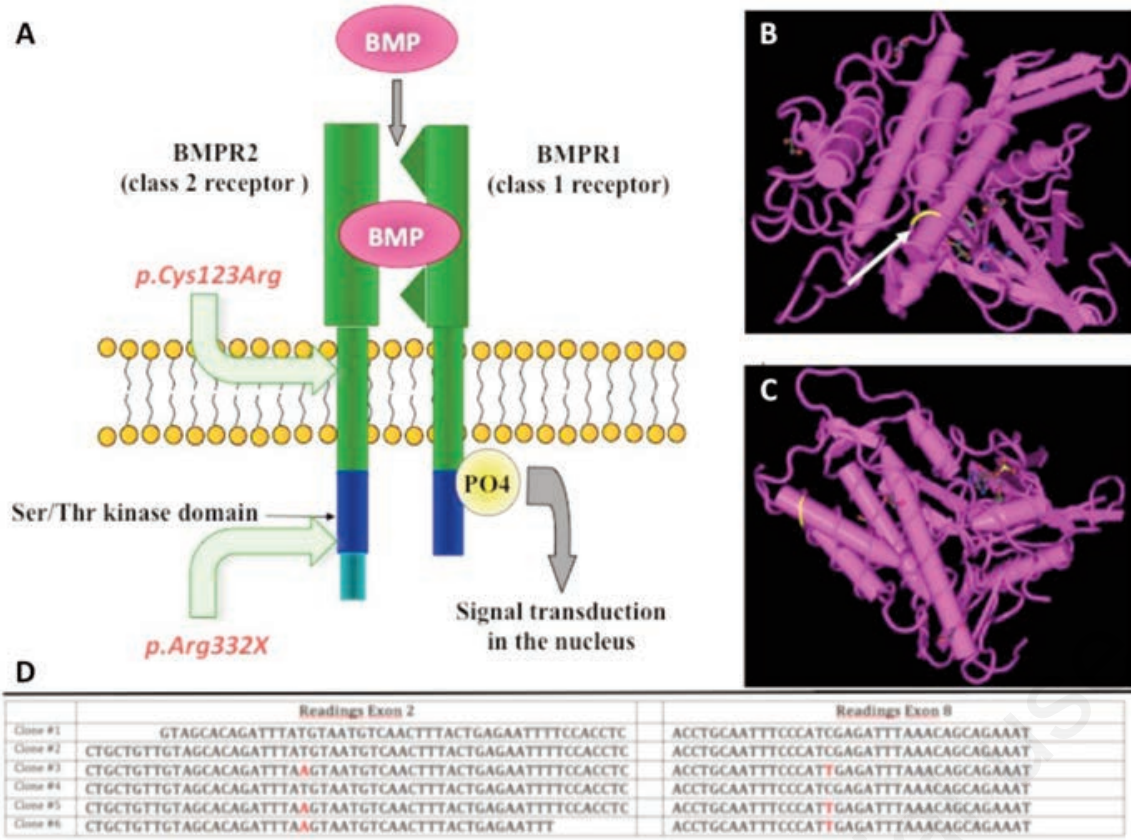

Figure 4. Molecular testing and protein modeling. A) BMPR2 receptor structure highlighting the positions of the two found mutations: the first within the transmembrane domain (p.Cys123Arg) and the second within the Ser/Thr-kinase domain (p.Arg332X). B) and C) PyMol software protein modeling highlighting in yellow the p.Cys123Arg mutation and the p.Arg332X mutation. D) Aligned clones resulting from next generation sequencing and analysis: clones always contain both mutations indicating that both mutations are on the same allele and do not segregate (cis position).

exon \#8 (p.Arg332X) (Figure 4). Both mutations have previously been associated with the IPAH phenotype (Table 3$)^{21,22}$ and were absent in 250 healthy controls (500 chromosomes); in silico analysis PolyPhen-2/Sift) confirmed the pathogenicity of the C123R mutation (data not shown). Additionally, the phase analysis by NGS revealed that both mutations were present on the same allele (cis-segregation; Figure 4).

\section{Discussion}

Heterozygous germline mutations in the BMPR2 gene have previously been implicated in the onset of $\mathrm{PAH}^{8}$ where they have been identified in approximately 10 to $40 \%$ of patients with cases of IPAH previously thought to have arisen spontaneously ${ }^{10,11}$ and in 58 to $74 \%$ of patients with HPAH. ${ }^{14-16}$ In this case study of a 38-year-old woman with a history of respiratory disease who presented with severe dyspnea, we identified two mutations in the BMPR2 gene which were in cis configuration. After 6 days of intensive care the patient had a severe fatal hemodynamic compromise which we feel could be attributed to the presence of the double/compound mutation of the BMPR2 gene identified. We speculate that gene dosage could have affected the severity of the PAH phenotype, which has been previously reported for other inherited cardiovascular diseases..$^{23}$ Girolami et al. described the clinical outcome of four patients with triple mutations in genes coding for sarcomere proteins and concluded that the multiple mutations conferred an increased risk of end-stage progression and ventricular arrhythmia. ${ }^{23}$

The major limitation of the present study is the family cascade screening: we could not have access either to the medical records and genetic material of parents and siblings. The presence of cis-mutations of the BMPR2 sug- gests that they might arise from one parental allele. However since both of them are living and self-reporting healthy, it can be speculated that one mutation is inherited and the second happened de novo in the germ line.

Carrying a single BMPR2 mutation per se does not imply developing PAH since heterozygous carriers of disease-causing BMPR2 mutations only have $20 \%$ chance of developing $\mathrm{PAH}$ over life times..$^{24}$ Thus multiple hits (including compound/double heterozygous mutations) are required to cause disease onset and progression in the BMPR2 mutations' carriers.

Taken together, these cardiac, genetic and pathological findings - although limited to the index case - provide further evidence of the role of the BMPR2 gene in PAH and its potential as a target for novel therapeutic interventions. In addition, the detection of these mutations may allow preclinical diagnosis of family members of the patient we observed who are currently asymptomatic but at risk of the onset of PAH disease symptoms.

\section{References}

1. Galie N, Hoeper MM, Humbert M, et al. Guidelines for the diagnosis and treatment of pulmonary hypertension. Eur Respir J 2009;34:1219-63.

2. Humbert M, Sitbon 0, Chaouat A, et al. Survival in patients with idiopathic, familial, and anorexigen-associated pulmonary arterial hypertension in the modern management era. Circulation 2010;122:156-63.

3. Voelkel NF, Gomez-Arroyo J, Abbate A, et al. Pathobiology of pulmonary arterial hypertension and right ventricular failure. Eur Respir J 2012;40:1555-65.

4. Peacock AJ, Murphy NF, McMurray JJ, et al. An epidemiological study of pulmonary arterial hypertension. Eur Respir J 2007;30:104-9.

5. Badesch DB, Raskob GE, Elliott CG, et al. Pulmonary arterial hypertension: baseline characteristics from the REVEAL Registry. Chest 2010;137:376-87.

6. Frost AE, Badesch DB, Barst RJ, et al. The changing picture of patients with pulmonary arterial hypertension in the United States: how REVEAL differs from historic and non-US Contemporary Registries. Chest 2011;139:128-37.

7. Humbert M, Sitbon 0, Simonneau G. 
Treatment of pulmonary arterial hypertension. N Engl J Med 2004;351:1425-36.

8. Dresdale DT, Michtorm DP, Schultz M. Recent studies in primary pulmonary hypertension, including pharmacodynamic observations on pulmonary vascular resistance. Bull N Y Acad Med 1954;30: 195-207.

9. Rich S, Dantzker DR, Ayres SM, et al. Primary pulmonary hypertension. A national prospective study. Ann Intern Med 1987;107:216-23.

10. Elliott CG. Genetics of pulmonary arterial hypertension: current and future implications. Semin Respir Crit Care Med 2005;26:365-71.

11. Ma L, Chung WK. The genetic basis of pulmonary arterial hypertension. Hum Genet 2014;133:471-9.

12. Deng Z, Morse JH, Slager SL, et al. Familial primary pulmonary hypertension (gene PPH1) is caused by mutations in the bone morphogenetic protein receptor-II gene. Am J Hum Genet 2000;67:737-44.

13. Lane KB, Machado RD, Pauciulo MW, et al. Heterozygous germline mutations in BMPR2, encoding a TGF- receptor, cause familial primary pulmonary hypertension.
Nat Genet 2000;26:81-4.

14. Sztrymf B, Coulet F, Girerd B, et al. Clinical outcomes of pulmonary arterial hypertension in carriers of BMPR2 mutation. Am J Respir Crit Care Med 2008;177:1377-83.

15. Grunig E, Weissmann S, Ehlken N, et al. Stress Doppler echocardiography in relatives of patients with idiopathic and familial pulmonary arterial hypertension: results of a multicenter European analysis of pulmonary artery pressure response to exercise and hypoxia. Circulation 2009;119:1747-57.

16. Rosenzweig EB, Morse JH, Knowles JA, et al. Clinical implications of determining BMPR2 mutation status in a large cohort of children and adults with pulmonary arterial hypertension. J Heart Lung Transplant 2008;27:668-74.

17. Machado RD, Eickelberg 0, Elliott CG, et al. Genetics and genomics of pulmonary arterial hypertension. J Am Coll Cardiol 2009;54:S32-42.

18. Pfarr N, Szamalek-Hoegel J, Fischer C, et al. Hemodynamic and clinical onset in patients with hereditary pulmonary arterial hypertension and BMPR2 mutations. Respir Res 2011;12:99.
19. Austin ED, Loyd JE, Phillips JA. III Genetics of pulmonary arterial hypertension. Semin Respir Crit Care Med 2009;30:386-98.

20. Wang G, Knight L, Ji R, Lawrence P, et al. Early onset severe pulmonary arterial hypertension with 'two-hit' digenic mutations in both BMPR2 and KCNA5 genes. Int J Cardiol 2014. [Epub ahead of print]

21. Machado RD, Pauciulo MW, Thomson JR, et al. BMPR2 haploinsufficiency as the inherited molecular mechanism for primary pulmonary hypertension. Am J Hum Genet 2001;68:92-102.

22. Thomson JR, Machado RD, Pauciulo MW, et al. Sporadic primary pulmonary hypertension is associated with germline mutations of the gene encoding BMPR-II, a receptor member of the TGF- family. J Med Genet 2000;37:741-5.

23. Girolami F, Ho CY, Semsarian C, et al. Clinical features and outcome of hypertrophic cardiomyopathy associated with triple sarcomere protein gene mutations. J Am Coll Cardiol 2010;55:1444-53.

24. Rabinovitch M. Molecular pathogenesis of pulmonary arterial hypertension. J Clin Invest 2012;122:4306-13. 